\title{
Aprendizagem histórica e formação de professores: contribuições da pesquisa em Educação Histórica
}

\author{
Geyso Dongley Germinari \\ Universidade Estadual do Centro-Oeste, Professor adjunto. \\ https://orcid.org/0000-0002-4797-7113 \\ Ana Claudia Urban ${ }^{2}$ \\ Universidade Federal do Paraná, Departamento de Teoria e Prática de Ensino, Setor de \\ Educação, Professora adjunta. \\ https://orcid.org/0000-0001-9957-8838
}

É com satisfação que apresentamos a seção temática Aprendizagem histórica e formação de professores: contribuições da pesquisa em Educação Histórica. A temática tem sido objeto de pesquisa e reflexão no campo de investigação em Educação Histórica. Essa área de pesquisa vem se definindo com suas especificidades próprias, em diferentes países e também no Brasil.

0 conjunto de pesquisadores que publicizam suas investigações nesta seção temática destaca o significado do debate sobre a aprendizagem histórica e a interface necessária com a formação de professores.

Os investigadores identificados com o campo de pesquisa em Educação Histórica têm focado seus estudos nos processos de aprendizagem histórica no espaço escolar, sob o pressuposto de que a qualidade do ensino exige o conhecimento sistemático dos caminhos percorridos para aprender história. Como pressuposto teórico, as pesquisas partem da natureza epistemológica do conhecimento histórico, e como pressuposto metodológico, realizam análises de ideias históricas de jovens, crianças e professores, definindo a sua especificidade com relação a outras pesquisas que tomam como objeto o ensino e aprendizagem da história.

Essas pesquisas podem ser agrupadas em duas tendências: a primeira reportase aos estudos acerca da cognição, que tendem mais para a Psicologia Cognitiva; e a outra, denominada Educação Histórica, dialoga mais estreitamente com os referenciais da epistemologia da história. Na segunda tendência, as pesquisas sobre aprendizagem histórica

Doutor e Mestre em Educação pela Universidade Federal do Paraná.

2 Doutora em Educação pela Universidade Federal do Paraná; Mestre em Educação pela Universidade Estadual de Ponta Grossa. 
têm como finalidade conhecer os processos de desenvolvimento do pensamento histórico de alunos e professores.

Considerando esse movimento das pesquisas, refletir sobre a aprendizagem histórica e a formação de professores é também apreender como se anunciam na consciência histórica de diferentes sujeitos determinadas formas de superação do pensamento pautado no etnocentrismo pelo pensamento fundamentado no humanismo histórico. Nessa direção, a aprendizagem histórica significa desenvolver progressivamente ideias balizadas pelo conhecimento histórico científico, como a pluralidade de interpretações e narrativas acerca do passado, o conceito de evidência histórica a partir de inferências em fontes e a noção de causalidade histórica.

0 conjunto de artigos que compõem a presente seção temática assume a pesquisa enquanto processo de produção do conhecimento histórico fundamental à própria natureza do trabalho do professor, que, ao tomar posse dos objetos, dos processos e dos procedimentos inerentes à produção do conhecimento, viabiliza a superação da divisão do trabalho que, historicamente, separou aqueles que produzem o conhecimento na universidade e aqueles que o transmitem na escola. Nesta direção, o conjunto de pesquisas apresentadas assume o professor de História como produtor de conhecimento, a partir de reflexões sobre as relações entre o seu trabalho e a ciência de referência.

0 artigo que abre a seção, Educação histórica e a contribuição para a formação de professores: experiências de pesquisa, elaborado pelos pesquisadores Geyso Dongley Germinari e Ana Claudia Urban (2020), indica alguns resultados de dissertações produzidas por mestrandos do Programa de Pós-Graduação Stricto Sensu em Educação da Universidade Federal do Paraná (UFPR) e dos Programas de Pós-Graduação Stricto Sensu em Educação e História da Universidade Estadual do Centro-Oeste (Unicentro). As pesquisas desenvolvidas no campo da Educação Histórica problematizam os processos de aprendizagem histórica no ambiente escolar.

0 artigo Estilos de enseñanza: punto de partida de la identidad y el desarrollo profesional docente, dos professores espanhóis María Begoña Alfageme-González e José Díaz-Serrano (2020), aborda o estilo de ensino de professores de Geografia e História do Ensino Secundário da Espanha. Os resultados apontam que na prática dos professores há equilibrio de estilos, com leve predominância dos estilos formal e funcional, tendo como parâmetro a teoria dos estilos de ensino-aprendizagem aplicada à educação.

Glória Solé (2020), professora auxiliar da Universidade do Minho (Portugal), no texto Aprendizagem histórica e formação de professores dos anos iniciais na Universidade do Minho (Portugal): a articulação entre a prática e a investigação em educação histórica, apresenta estudos empíricos realizados pelos acadêmicos de mestrados profissionais de formação de 
professores da Universidade do Minho. Na perspectiva da pesquisa em cognição histórica os estudos versam sobre conceitos de segunda ordem, consciência histórica e educação patrimonial aplicados à educação básica em Portugal.

A formação de professores de História, na perspectiva da Educação Histórica, foi tema do artigo $A$ aula-oficina na caminhada de aprender a ser professor de história, da pesquisadora Marilia Gago (2020), da Universidade do Minho. A autora indica, como possibilidade para formação de professores de História, o trabalho com a metodologia da aula-oficina criada no âmbito da Educação História. A proposta aponta um caminho para o desenvolvimento da literacia e consciência histórica em aulas de história. A pesquisa de natureza qualitativa realizada com 20 alunos do mestrado em ensino da História de uma universidade do Norte de Portugal demonstrou que os futuros professores de História entendem que a aplicação da proposta da aula-oficina e o debate contínuo acerca dos problemas do ensino promovem a consciência do seu papel e propósito de professor de História.

0 investigador Thiago Augusto Divardim de Oliveira (2020), do Instituto Federal do Paraná (Campus Curitiba), apresenta no artigo Pressupostos da pesquisa e da formação continuada de historiadores docentes: uma contribuição da educação histórica possibilidades de organização dos pressupostos teóricos e empíricos relativos aos trabalhos desenvolvidos pelo Laboratório de Pesquisa em Educação Histórica, da Universidade Federal do Paraná (Lapeduh/UFPR), no que se refere aos cursos de formação continuada de professores de História, ministrados na rede pública de ensino do Estado do Paraná.

0 artigo Formação inicial e continuada de professores(as) de história: impactos na prática docente, de autoria das professoras Maria Cristina Dantas Pina, Edinalva Padre Aguiar e Iracema Oliveira Lima (2020), da Universidade Estadual do Sudoeste da Bahia, problematiza em que medida a formação em diferentes níveis influencia a prática docente de professores de História que atuam na Educação Básica do Estado da Bahia. A reflexão insere-se no projeto "Ensinar história: um estudo sobre as práticas de ensino e a produção de narrativas históricas por professores de história da educação básica (Paraná - São Paulo - Bahia Goiás 1998-2014)". A análise dos dados, obtidos por intermédio de questionário, indica que não há variações relevantes que evidenciam aprimoramento da prática docente por tempo de serviço e grau de formação; no entanto, nas questões relativas à narrativa histórica, alguns professores com mestrado e graduação recentes apresentam relatos mais atualizados e com maior nível de complexidade.

0 pesquisador Erinaldo Vicente Cavalcanti (2020), da Universidade Federal do Sul e Sudeste do Pará, em seu artigo 0 que deve aprender o professor de história? Reflexões sobre aprendizagem, ensino e formação docente, analisa matrizes curriculares dos cursos de história oferecidos nas universidades federais da região amazônica do Brasil. 0 objetivo da pesquisa é reconhecer o lugar da Educação Histórica na formação inicial de professores 
de História. A verificação indicou que as licenciaturas pesquisadas não priorizam o ensino de História de modo geral e praticamente ignoram a perspectiva da Educação Histórica.

Em $A$ aula de história: a experiência e a biografia docente na produção do conhecimento escolar de história, o professor Everton Carlos Crema (2020), da Universidade Estadual do Paraná, discute os processos criativos de professores de História (rede pública de ensino de União da Vitória, Estado do Paraná) quando organizam os conteúdos e as metodologias de ensino para aula. A partir da biografia profissional dos docentes e da análise das suas práticas didático-metodológicas, observou-se que o preparo das aulas se desenvolve mediado pela experiência profissional e pela cultura da escolar, um movimento que foi denominado produção estética da aula.

0 texto 0 ensino de história e o PIBID história UFC: práticas docentes a partir da história pública, escrito por Ana Carla Sabino Fernandes (2020), da Universidade Federal do Ceará, fecha o conjunto de artigos desta seção. Nele, a pesquisadora expõe atividades docentes de ensino e aprendizagem de história orientadas pela História Pública. As atividades realizadas em três escolas públicas do Estado do Ceará (2015-2018) foram organizadas no formato de aula-oficina e sequências didáticas e fizeram parte do Programa Institucional de Bolsa de Iniciação à Docência (PIBID/Subprojeto História) da Universidade Federal do Ceará.

Ainda, como parte da seção temática, Solange Maria Nascimento (2020), doutoranda do Programa de Pós-Graduação em Educação (PPGE) da Universidade Federal do Paraná, e Maria Auxiliadora Moreira dos Santos Schmidt, pesquisadora da Universidade Federal do Paraná, apresentam uma entrevista realizada com a Professora Doutora Isabel Barca, da Universidade do Minho (Portugal), a qual é referência no campo da Educação Histórica e cujos estudos têm grande inserção e impacto nas pesquisas brasileiras e internacionais.

A seção temática finaliza com a resenha escrita pela professora/pesquisadora Nikita M. Sukow (2020) (Lapeduh/UFPR) do livro Desenvolvendo o pensamento histórico: abordagens conceituais e estratégias didáticas, de autoria de Arthur Chapman, professor associado em Educação Histórica do Institute of Education da University College London.

Consideramos que há um caminho a ser percorrido no que diz respeito ao processo de formação de professores de História, porém tal caminho pode se fortalecer em debates e reflexões à medida que compartilhamos e analisamos ações alinhadas com esta preocupação: superação da dicotomia entre teoria e prática.

\section{REFERÊNCIAS}

ALFAGEME-GONZÁLEZ, M. B.; DíAZ-SERRANO, J. Estilos de ensino: ponto de partida da identidade e desenvolvimento do professor profissional. Roteiro, v. 45, p. 1-22, 19 jun. 2020. 
CAVALCANTI, E. V. 0 que deve aprender o professor de História? Reflexões sobre aprendizagem, ensino e formação docente inicial. Roteiro, v. 45, p. 1-22, 15 jun. 2020.

CREMA, E. C. A aula de História: a experiência e a biografia docente na produção do conhecimento escolar de História. Roteiro, v. 45, p. 1-24, 22 jul. 2020.

FERNANDES, A. C. S. 0 ensino de história e o PIBID História UFC: práticas docentes a partir da história pública. Roteiro, v. 45, p. 1-16, 29 jul. 2020.

GAGO, M. A aula-oficina na caminhada de aprender a ser professor de História. Roteiro, v. 45, p. 1-18, 17 jun. 2020.

GERMINARI, G. D.; URBAN, A. C. Educação histórica e a contribuição para a formação de professores: experiências de pesquisa. Roteiro, v. 45, p. 1-22, 16 jun. 2020.

NASCIMENTO, S. M.; SCHMIDT, M. A. M. DOS S. Entrevista: Educação histórica e sua influência na formação de professores e em documentos curriculares em Portugal. Roteiro, v. 45, p. 1-18, 28 jul. 2020.

OLIVEIRA, T. A. D. DE. Pressupostos da pesquisa e da formação continuada de historiadores docentes: uma contribuição da Educação Histórica. Roteiro, v. 45, p. 1-24, 15 jun. 2020.

PINA, M. C. D.; AGUIAR, E. P.; LIMA, I. O. Formação inicial e continuada de professores(as) de história: impactos na prática docente. Roteiro, v. 45, p. 1-24, 22 jul. 2020.

SOLÉ, G. Aprendizagem histórica e formação de professores dos anos iniciais na Universidade do Minho (Portugal): a articulação entre a prática e a investigação em educação histórica. Roteiro, v. 45, p. 1-26, 15 jun. 2020.

SUKOW, N. M. Resenha: Desenvolvendo o pensamento histórico: abordagens conceituais e estratégias didáticas. Roteiro, v. 45, p. 1-6, 27 jul. 2020.

Endereço para correspondência: Rua Professora Maria Roza Zanon de Almeida, s/n, Irati, Paraná, Brasil; geysog@gmail.com

Roteiro, Joaçaba, u. 45, p. 1-6, jan./dez. 2020 | e24849 |E-ISSN 2177-6059 
